\title{
О перспективах обнаружения месторождений офсетных апатит-нефелиновых руд в районе Хибинского массива
}

\section{Жиров Д.В.}

Геологический институт КНЦРАН, Anamumbl, zhirov@geoksc.apatity.ru

Аннотация. В статье предложено новое поисковое обоснование в отношении месторождений офсетных апатит-нефелиновых руд в районе Хибинского массива. Детально рассмотрены тектонические предпосылки формирования офсетных залежей - останцов толщи фоидолитов и руд в месте первичного залегания после реидного перемещения руд и протрузивного поднятия центральной части Хибинского плутона. На примере восточной части массива разработан прогноз локализации офсетных апатит-нефелиновых руд.

Ключевые слова: месторождение, рудное тело, разлом, поиск, апатит-нефелиновый.

\section{On prospects for discovery of off-set apatite-nepheline deposits in the Khibiny massif area}

\author{
Zhirov D.V. \\ Geological institute KSC RAS, Apatity,zhirov@geoksc.apatity.ru
}

\begin{abstract}
The article suggests a new basis for prospecting deposits of off-set apatite-nepheline ores in the Khibiny massif area. It allows extending the prospect area of commercially valuable objects. The paper provides a detailed study of the tectonic background that preconditioned the off-set deposits, i.e. outliers of a foidolite complex and ores at the primary bedding site after a flowable ore movements and protrusive uplift of the central Khibiny pluton. A forecast of the off-set apatite-nepheline ores localization has been made based on the example of the eastern part of the Khibiny massif.
\end{abstract}

Key words: deposit, ore body, fault, prospects, apatite-nepheline.

\section{Введение}

Поисковая модель (ПМ) локализации рудных тел является необходимым условием эффективного и рационального поиска и разведки месторождений полезных ископаемых (ПИ). Как правило, ПМ должна описывать основные поисковые предпосылки, включая структурные, литологические или петрологические факторы контроля, а также ожидаемую глубину и условия залегания, масштаб: мощность, протяжённость рудных тел по простиранию и падению, качество ПИ. Чем адекватнее она отражает эти особенности, тем быстрее и эффективнее в экономическом и результативном смыслах осуществляются геологоразведочные работы (ГРР). Поисковые модели бывают простые и сложные, частично или полностью совпадающие с реальными, фактическими параметрами. Если хорошо работает только ряд поисковых признаков, то нет необходимости увеличивать их количество и усложнять модель, однако, если вследствие их ограниченности могут быть пропущены «цели», то ПМ нуждается в доработке. Как правило, модели развиваются от простых к сложным, совершенствуясь и дополняясь по мере обнаружения новых рудных тел и их частей в нетипичных геологических обстановках. Нечасто, но бывает и наоборот: изменение прогнозных представлений об условиях локализации рудных тел приводит к открытию новых месторождений. Хорошо известными примерами служат открытие месторождения медно-никелевых руд Заполярное (Печенгская структура), которое было обнаружено благодаря новой ПМ, предложенной главным геологом Главникелькобальта МЦМ СССР Г.Д. Вареня (Медно-никелевые ..., 1999) и открытие Кольской платинометалльной провинции на основе рекомендаций и прогнозных построений директора ГИ КНЦ РАН Ф.П. Митрофанова (Митрофанов Ф.П. и др., 1999).

История открытий Хибинских апатит-нефелиновых месторождений прошла через смену нескольких вариантов относительно простых модельных представлений. При этом вне зависимости различий в интерпретации последовательности образования интрузивных комплексов и в оценке соотношения магматических / метасоматических процессов все эксплуатирующиеся и подготовлен- 
ные к промышленному освоению месторождения были открыты и разведаны в пределах одной рудоконтролирующей структуры - ийолит-уртитовой дуги (ИУД) или в современных терминах - конических интрузий фоидолитов. Приуроченность апатит-нефелиновых руд к ИУД была отмечена А.Е. Ферсманом (Ферсман, 1929) и подтверждена первыми же поисковыми работами 1929-1930 гг. под руководством Б.М. Куплетского и В.Н. Влодавца, в результате которых были открыты месторождения Кукисвумчорр, Юкспорр и Расвумчорр (Куплетский, 1930; Геология..., 2002). В дальнейшем поисковая модель дополнялась деталями, которые в различной степени отразились на результативности. Так первооткрыватель нескольких месторождений - Е.А. Каменев (Каменев, 1975, 1987; Зак и др., 1972; Новые..., 1982) увязывал локализацию промышленного оруденения с морфологией и гипсометрическим уровнем подошвы (лежачего контакта) рудных тел. Его построения оказались полезными для разведки глубоких горизонтов крупных месторождений. Ф.М. Онохин (Онохин, 1975) предложил модель поисков новых месторождений, основанную на представлениях о дифференцированных вертикальных сбросо-взбросовых движениях крупных блоков по радиальным разломам. Эти построения и прогнозные обоснования на их основе стали одной из причин реализации уникального поискового проекта (1970-1973 гг.) с проводкой глубоких (до 2 км) скважин. По его результатам было уточнено строение и предварительно разведаны запасы Эвеслогчоррского месторождения, а также обнаружены проявления Вуоннемъок и Малый Вудъявр. В целом к середине 1980 гг. были открыты все известные промышленно-значимые месторождения и проявления Хибинского массива (ХМ). Было также несколько поисковых обоснований на слепые залежи и россыпи апатита, однако значимых результатов они не принесли. В период, начиная с конца 1980-х и по настоящее время, преимущественно выполнялись разведка и доразведка флангов и на глубину эксплуатирующихся месторождений. В советский период времени, по оценке Е.А. Каменева (устное сообщение), на воспроизводство фосфатной сырьевой базы, в т.ч. на поиски, тратилось в среднем 2\% от стоимости добытых руд. Сейчас (2018-2019 гг.) этот показатель вряд ли превышает первые десятые долей процента. Вместе с тем накоплена критическая масса новых данных и результатов геолого-геофизических и тектонофизических исследований, позволяющих по-новому взглянуть на механизм формирования месторождений и применить ранее неиспользовавшиеся факторы структурного контроля их размещения и морфологии. Есть все предпосылки для разработки новой поисковой модели формирования рудных тел и месторождений, что позволит наметить перспективные, ранее неопоискованные участки. При этом предлагаемая модель должна не отвергать, а дополнять и уточнять ранее апробированные представления.

\section{Поисковое обоснование обнаружения офсетных руд}

Какие из ранее не учтённых факторов могут существенно дополнить существующие, многократно апробированные? Во-первых, к ним относится вязко-пластическая и пликативная тектоника фоидолитов и, прежде всего, рудных тел. Большинство исследователей отмечали их распространение и проявление на всех месторождениях (Онохин, 1975; Каменев, 1987 и др.), но при этом им не уделялось соответсвующего внимания, прежде всего, в связи с тем, что их фактическое влияние на локализацию и масштаб рудных тел минимальное. Вместе с тем вязкопластические сдвиги, складки обычные и «волочения», затекание и перетекание руды в карманы и ниши, мультистадийное брекчирование руд и вмещающих пород с частым проявлением прямых и обратных геологических соотношений, - всё свидетельствует о весьма интенсивном проявлении недизъюнктивной тектоники. Половина из 8-9 выделяемых типов руд (основные типы: пятнистые, полосчатые, линзовидно-полосчатые, блоковые, сетчатые, массивные, брекчиевидные и второстепенные: апатит-титанитовые и апатитсодержащие уртиты) имеет отчётливые следы вязкопластических деформаций (рис. 1), а для большинства остальных они проявляются периодически. Незаслуженное внимание к этому аспекту можно объяснить незначительным влиянием пластических деформаций на геометрию, локализацию и масштаб рудных тел, так как все они приурочены ко внутренней части рудных тел и за их пределы, как правило, не выходят. То есть, ни условия залегания, ни линейные параметры тел они практически не меняют. Вязко-платическая тектоника правильно 

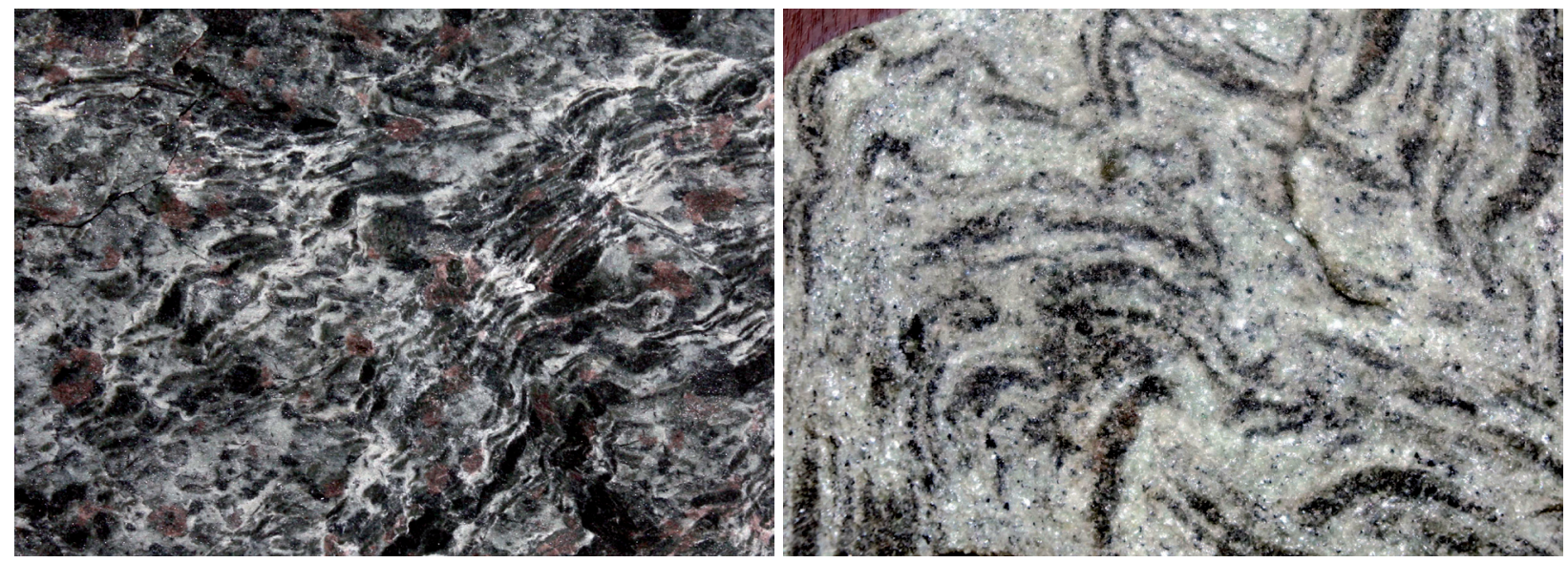

Рис. 1. Примеры вязко-пластической и пликативной тектоники в апатит-нефелиновых рудах.

Fig. 1. Examples of viscous flow and plicative tectonics in apatite-nepheline ores.

объясняет механизм образования «складок волочения», которые многократно документировали и описывали на месторождениях южного группы. Их образованию способствовало не смещение висячего крыла вмещающих пород (Онохин, 1975), а торможение растекающейся пластичной руды об это крыло. Фактор вязко-пластического течения важен в связи с возможностью перетекания и перераспределения руды из мест первичного залегания в новое месторасположение.

Вторым фактором, логически связанным с вязко-пластической тектоникой, служит характерная вертикальная зональность рудных тел. Если построить типовой разрез целого (неэродированного) рудного тела, то можно отметить следующие закономерности (рис. 2). При общей линзовидной морфологии рудные тела в приповерхностных (в приконтактовых) частях характеризуются повышенной мощностью (горизонтальной и истинной), удельной долей (представительностью) богатых разновидностей руд и выполаживанием с налеганием на вершину гор и с образованием своеобразной «шапки» - субгоризонтального раздува, наплыва на поверхность вмещающих пород.

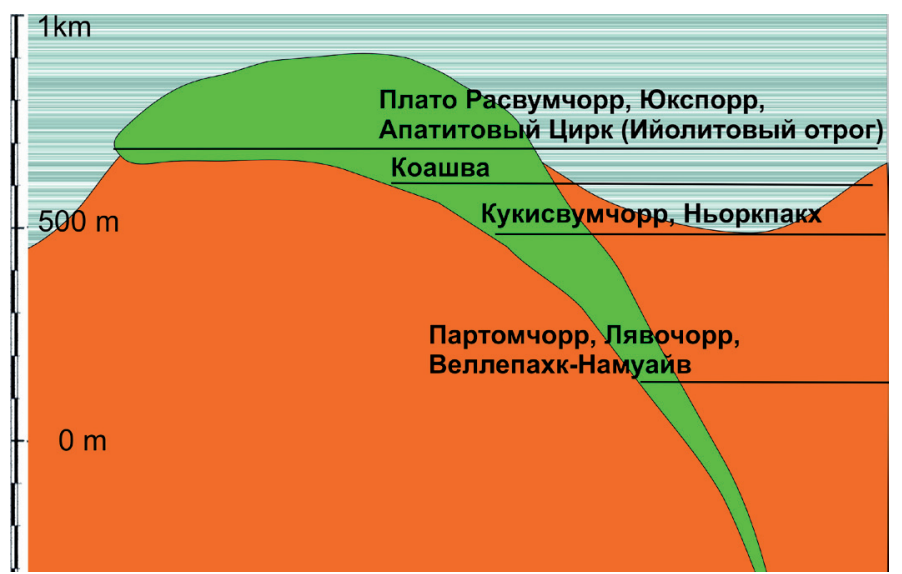

Рис. 2. Гипотетический полный разрез рудной залежи Хибин с примерной оценкой глубины эрозии известных месторождений. Оранжевым цветом обозначены вмещающие щелочные породы без расчленения, зелёным - комплекс фоидолитов с рудными телами.

Fig. 2. Hypothetic full section of the Khibiny ore deposit with approximately estimated erosion depths of the known deposits. Yellow color indicates host alkaline rocks with no separation. Green color indicates a complex of foidolites with ore bodies with no separation.

Возможное объяснение этого феномена - реидное выдавливание, перетекание и заполнение рудой ослабленной зоны в приконтактовой, апикальной части массива. Вероятно, этому способствовал полистадийный характер магматизма, когда в ходе многочисленных инъекций по коническому кольцевому разлому каждые последующие порции магмы расширяли, раздвигали поверхность гидроразрыва (собственно Главного конического разлома) с образованием раздува в области ранее сформированной поверхности раздела между щелочными породами и вмещающими кристаллическими и/или осадочными породами. Под действием силы тяжести вышележащей толщи и, возможно, кристаллизационных сил пластичная руда выдавливалась к границе раздела и заполняла структурные линзовидные «карманы и ловушки», как в приповерхностной части, так и на глубине (рис. 3). 

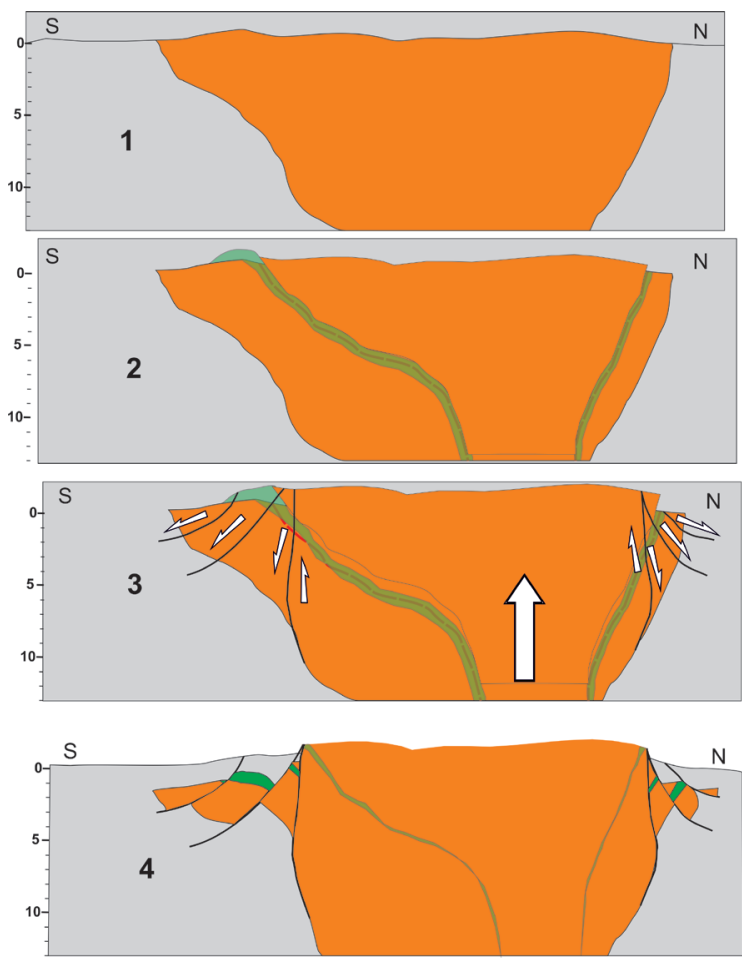

Рис. 3. Принципиальная схема формирования офсетных залежей Хибин.

1 - фаза формирования расслоенного щелочного интрузива (лополита); 2 - фаза формирования конического разлома и интрузий фоидолитов; 3 - фаза интенсивного реидного постумного (протрузивного) воздымания центральной части Хибин; 4 - примерное расположение офсетных «разъехавшихся» блоков с рудовмещающими фоидолитами.

Fig. 3. Basic scheme of the off-set deposits formation in the Khibiny.

1 - phase of formation of a layered alkaline intrusion (lopolith); 2 - phase of formation of a ring (cone-like) fault and foidolite intrusions; 3 - phase of an intensive flowable posterior (protrusive) uplift of the central part of the Khibiny; 4 - approximate location of off-set «separated» blocks with ore-bearing foidolites.

Останцы подобных «шапок» известны на «Ийолитовом отроге» (в среднем 20-25 м до 40 м вертикальной мощности богатых руд) и участке «Нагорный»- Юкспорр(от 1-5 до 48 м). Весьма вероятно, что эти образования были характерны для большинства известных месторождений, имели существенно бо'льшую мощность (до 100-150 м) и состояли в основном из богатых разновидностей руд (полосчатых, массивных, линзовидно-полосчатых, брекчиевидных). В ходе мезозой-кайнозойской эволюции ХМ эти «шапки» на большей части ИУД были эродированы. В отношении некоторых других участков имеются особые обстоятельства, предполагающие сохранность «шапок».

Третьим важным фактором являются особенности тектоники плутона, выявленные по результатам наших тектонофизических исследований 2012-2018 гг. (Жиров и др., 2016; Zhirov \& Zhirova, 2018). Установлено, что на отрезке времени, начиная с нижнего мезозоя (верхний триас) до плейстоцена, ХМ испытал значительный постумный протрузивный подъём со срывом, разрушением краевых приконтактовых частей и образованием структур «псевдосброс» (см. рис. 3). Там, где ИУд подходила близко к внешней границе плутона (В, ЮВ и СВ части), создались все предпосылки для срыва приповерхностных, наиболее фертильных её частей с последующей консервацией в месте первоначального залегания. Центральная же часть массива была эксгумирована и подвергалась эрозии и выветриванию.

В современном рельефе горного массива Хибин, в его краевых частях хорошо дешифрируются многочисленные ступенчатые и унитарные «псевдосбросы» с суммарным видимым смещением от 300 до 500 м. Их поверхность имеет хорошо выраженные признаки кинематики сброса (рис. 4 а). Одно из таких мест расположено на восточном склоне г. Суолуайв, где видимая, выходящая на дневную поверхность часть «псевдосброса» составляет минимум 3 км по горизонтали и не менее 370 м по вертикали, а предполагаемая - не менее 4.5 км по простиранию и до 1 км и, возможно, более по падению (см. рис. 4 a, 4б). Также для него характерно постепенное выполаживание от 55-65 у вершины плато до $35-45^{\circ}$ у подножия. Комплекс рудоконтролирующих фоидолитов при приближении к современной платообразной вершине выполаживается (см. рис. 4 б), однако наиболее мощная, раздутая часть его оказалась в сброшенной части. Таким образом, в месте первоначального залегания осталась потенциально наиболее продуктивная «шапка». То есть, мы имеем тектонически обоснованные предпосылки для поисков офсетных руд. 

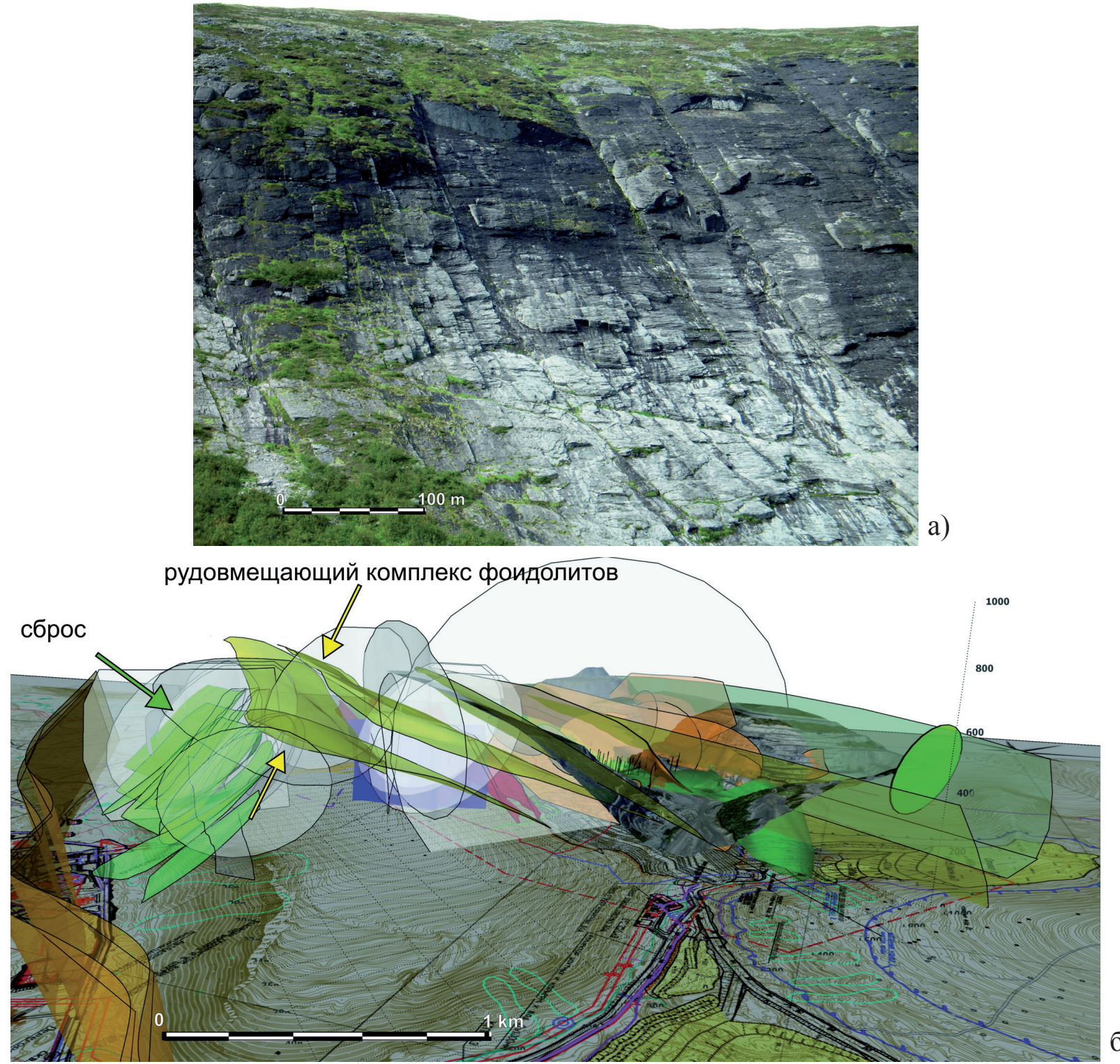

Рис. 4. Псевдосброс на ЮВ склоне г. Суолуайв (а). Сброс состоит из множества сближенных между собой поверхностей (лепестков) отдельных сместителей, которые в целом формируют протяжённый магистральный разлом. Положение рудовмещающего комплекса фоидолитов относительно псевдосброса (б).

Fig. 4. Pseudo-fault at the south-eastern slope of Mt. Suoluayv (a). The fault consists of numerous adjacent surfaces («petals») of individual displacements, which jointly form the extensive main fault. The position of the ore-bearing foidolites relative to pseudo-fault (b).

При геометризации рассматриваемого участка недр, перспективного на поиск «погребенных» офсетных апатит-нефелиновых руд, необходимо учесть следующие факторы: 1) фактическое смещение по псевдосбросу составляет не менее 450-500 м; максимальное может составлять до 1.0-1.2 км (максимальное превышение Хибин над окружающим рельефом с учётом приблизительной оценки эродированной части «шапки» в районе месторождений Плато Расвумчорр и Апатитовый Цирк); 2) воздымание центральной части Хибин с одновременным сползанием краевых частей сопровождалось как вертикальными, так и горизонтальными смещениями, что даёт при учете среднего угла падения сместителя в 30-35 ${ }^{\circ}$ горизонтальную составляющую, в 1.2-1.5 раза превышающую вертикальную. В соответствии с этими представлениями наиболее перспективный участок недр располагается к ЮВ и В от г. Суолуайв на горизонтальном расстоянии от 100-200 м от подножия до середины оз. Умбезеро (1.5-1.8 км) включительно, а предполагаемая глубина залегания кровли останца рудоконтролирующего комплекса фоидолитов в зависимости от варианта оценки абсолютной вели- 
чины смещения варьирует от 200-250 м до 950-1000 м от дневной поверхности. Наиболее вероятная глубина подсечения ожидается в пределах 250-350 м.

Оценку потенциала офсетных руд можно выполнить, отталкиваясь от представительности руд месторождений Олений Ручей и Ньоркпахк во вмещающем фоидолитовом комплексе и среднего содержания $\mathrm{P}_{2} \mathrm{O}_{5}$. Объёмное соотношение руд и вмещающих фоидолитов варьирует в пределах 0.01-0.34 (0.12 в среднем), а среднее качество руды в геометризованных телах месторождений составляет 13-15 \% $\mathrm{P}_{2} \mathrm{O}_{5}$. Принимая за исходные данные длину псевдосброса вдоль В и ЮВ склона г. Суолуайв (до месторождения Ньоркпахк), равную 4.2-4.4 км, а вертикальную мощность «шапки» 150 м при средней предполагаемой ширине «сброшенного» участка плато вершины 300-400 м, получим порядок цифр прогнозных запасов 25-29 млн. м³ или 75-95 млн. тонн руды со средним содержанием 13-15\% $\mathrm{P}_{2} \mathrm{O}_{5}$. Несомненно, что модель на данном этапе не может учесть все возможные осложняющие и, наоборот, упрощающие факторы, поэтому для её проверки необходимо выполнить минимум один опорный поисковый профиль из нескольких скважин с глубиной их проводки в 500-800 м.

Исследования выполняются в рамках раздела «Инновационные технологии и методы сбоpa, обработки и анализа геолого-геофизических данных в целях эффективного и безопасного освоения глубоких горизонтов месторождений стратегических полезных ископаемы» плановых НИР № 0226-2019-0053.

\section{Литература}

1. Медно-никелевые месторождения Печенги (отв. ред. Н.П. Лаверов). М. ГЕОС. 1999. 236 с.

2. Митрофанов Ф.П. и др., Кольская платинометальная провинция: новые данные. В кн.: Платина России. Кн. 1. Москва ЗАО «Геоинформмарк». 1999. С. 43-52.

3. Ферсман А.Е. Проблема Хибинских и Ловозерских тундр / Природа. № 51929.

4. Куплетский Б.М. Геологическое строение Кукисвумчорра по данным работ 1930 г. // Хибинские апатиты. Т. 2. Л.: ГОНТИ. Ленхимсектор. 1932. С. 392-395.

5. Каменев Е.А. Геология и структура Коашвинского апатитового месторождения. Л. Недра. 1975. 128 с.

6. Каменев Е.А. Поиски, разведка и геолого-промышленная оценка апатитовых месторождений хибинского типа (Методические основы). Л. Недра. 1987. 188 с.

7. Зак С.И., Каменев Е.А., Минаков Ф.В., Арманд А.Л., Михеичев А.С., Петерсилье И.А. Хибинский щелочной масснв. Л. Недра. 1972.176 с.

8. Новые хибинские апатитовые месторождения (под ред. Е.А. Каменева, Д.А. Минеева (ИМГРЭ, Севзалгеология, МГРИ). М. Недра. 1982. 182 с.

9. Пожиленко В.И., Гавриленко Б.В., Жиров Д.В., Жабин С.В. Геология рудных районов Мурманской области (под ред. Митрофанова Ф.П., Бичука Н.И.). Апатиты. Изд-во: КНЦ РАН. 2002. 359 с.

10. Dmitry Zhirov, Anzhela Zhirova Neotectonics of the Khibiny alkaline massif / Conference Proceedings SGEM2018. Albena (Bulgaria) 30 June -09 July 2018. 2018. Issue 1.1 Science and Technologyin Geology, Exploration and Mining. P. 355-362.

11. Жиров Д.В., Сим Л.А., Маринин А.В. Реконструкция палео стресс состояний в южной части Хибинского плутона (Восток Фенноскандинавского щита) / Труды конференции «Актуальные проблемы динамической геологии при исследовании платформенных областей». Москва. МГУ. 24-26 мая 2016. М. Изд-во: Перо. 2016. С. 39-44. 